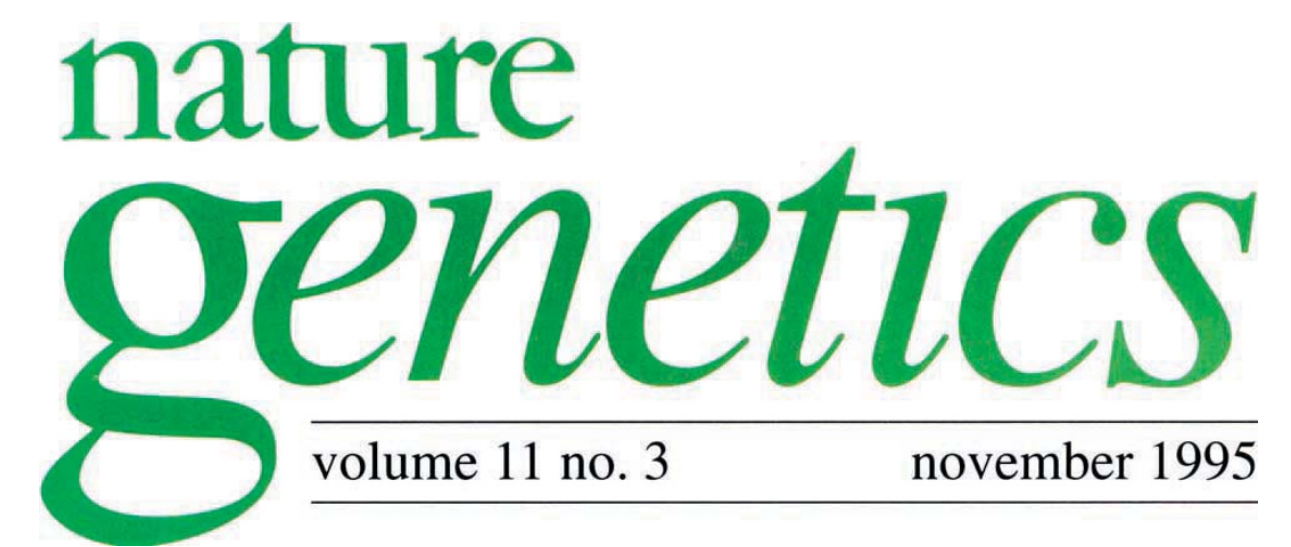

\title{
Crimes against genetics
}

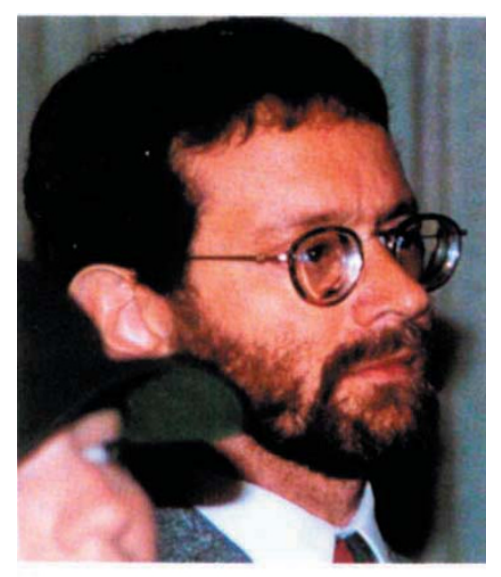

Conference organizer, David Wasserman, looks on (top) as protestors invade the conference (bottom).

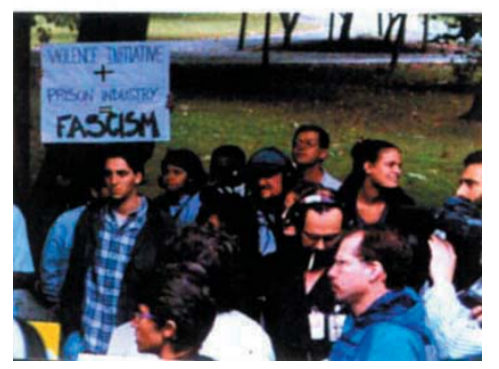

*The Meaning and Signiflcance of Research on Genetics and Criminal Behavior, Aspen Institute Wye Center, Queenstown, Maryland, September 2224, 1995.
Between shouts of "Jobs, yes! Drugs, no!" and extremely brief glimpses of behavioural genetics data, the controversial conference on genetics and criminal behaviour* was at times no more than a wordless reflection of miscommunication and misunderstanding. The conference was originally scheduled to occur three years ago, but was cancelled when the National Institutes of Health, under a deluge of protests about the conference's alleged racist implications, withdrew its funding. The conference, redesigned to include an unusually heterogeneous group of speakers (including criminologists, historians and philosophers), was rescheduled and held in rural Maryland in September despite continued protests. One thing was clear during the turbulent meeting; the issues involved in behavioural genetics research go far beyond the usual questions at scientific meetings - namely how good is the science?

The primary goal, as set out by the organizer, David Wasserman of the University of Maryland, was to explore the implications of current genetic research of violent, antisocial and criminal behaviour. The apparent hope in establishing the causes, as indicated by Diana Fishbein of the US Justice Department, is that pinpointing genes related to such complex behavioural traits as aggression or antisocial behaviour may help to identify and aid those most likely to fall victim to sociological circumstances. The fear, however, is that these studies will lead only to the enslavement of the underclasses as social changes are abandoned in favour of easy-answer drug treatments or harsh restrictions on those deemed genetically irredeemable.

Although it was unrealistic to expect any profound new insights or consensus to emerge during the hurried two-day meeting, progress will be hampered as long as there remains such difficulty in defining or quantifying behaviour types. Adrian Raine, of the University of Southern California, pointed out that schizophrenia is a disorder with a strong genetic basis (as is shown by several reports, pp. 287, 321, 325 and 235 of this issue, that all show linkage to chromosome $6 \mathrm{p}$ ); but, schizophrenia research has been plagued by changes in the definition of schizophrenia. The effect (as in any complex trait) is clear when one considers the history of genetic research on mental disorders. Such difficulties continue, as is shown by several more reports in this issue (pp. 233-234) that fail to show definitive linkage to chromosome 6p. Differences in populations, diagnostic models and the markers used in these studies as well as the potential heterogeneity of this disorder are all possible reasons for these inconsistent outcomes.

Defining behaviours for the single purpose of scientific reliability, however, was not the main issue of contention at the conference that was instead the implications of the definitions for society. A graphic illustration came when David Comings, of the City of Hope 


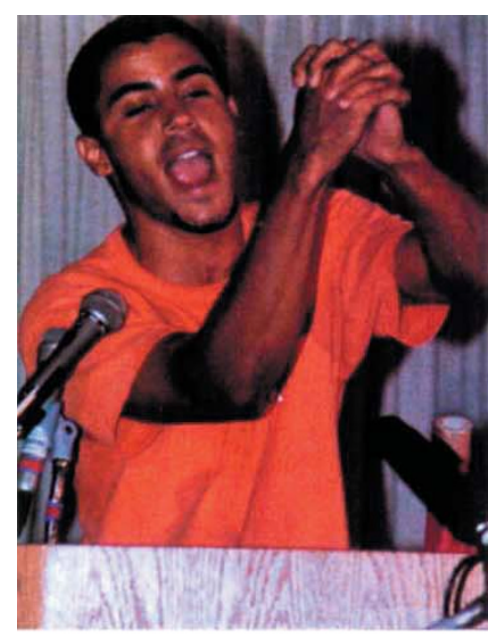

Demonstrators seized the podium to present their view of behavioural genetics research.

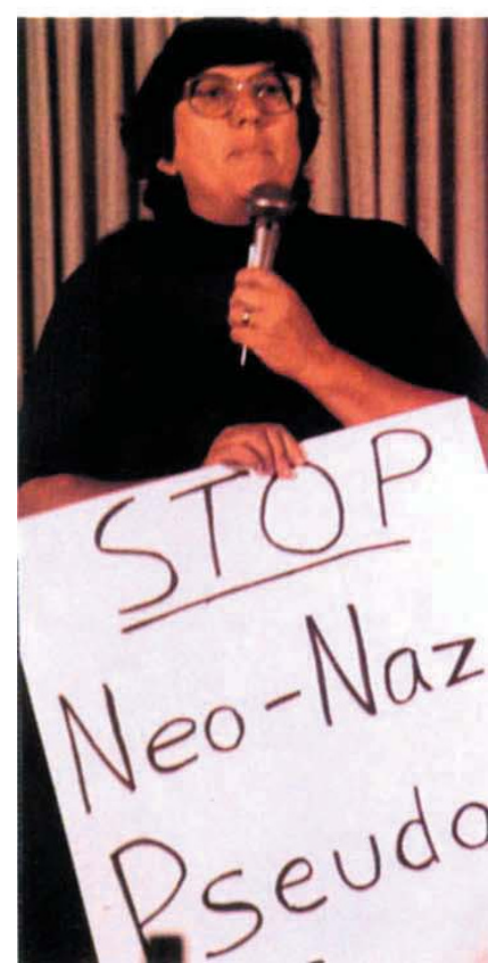

Medical Center in California, provided the American Psychiatric Association's criteria in its Diagnostic and Statistical Manual of Mental Disorders (DSM-III-R) for diagnosing an individual with attention-deficit hyperactivity disorder; an audience member remarked that some might use a similar list to describe a young black male. The audience member's point, though extreme, was meant to illustrate that precise definitions of some diagnostic terms are debatable and thus create the potential for personal and socially based biases to affect such research. Some speakers expressed the opinion that historical misuse of science was no longer of great concern; however, Paul Billings of Stanford University Hospital and one of six to present a written formal protest of the meeting, warned that our present ideas of moral responsibility may be no more enlightened than those of a century ago and we may therefore be no less likely to commit atrocities based on scientific discoveries.

Many of the scientists, hurt at being so inaccurately depicted as racist or fascist, repeatedly stated that all their work had been done in Caucasians; that there were no racial comparisons in genetics and criminal behaviour studies; and that this work had nothing to do with inner city problems. Nevertheless, Pilar Ossorio, one of the speakers discussing the political implications of this work, pointed out that the word 'crime' carries a race label because, in the United States, there is a biased public perception of who the criminals are. What makes this particularly dangerous is that the public also sees scientific information, regardless of the soundness of the methods, as powerfully legitimizing, and, furthermore, the public's perception of genetic findings is that they are immutable. Thus the mere perception of reality (rather than the realities themselves) can provide impetus for the enactment of inequitable laws; at the turn of the century, concern about the rise in poverty and the unhealthy moral influences of the poor combined with the public impression of the power of genetics led to the forced sterilization of thousands in the United States, an idea that reached its pinnacle in Nazi Germany.

The human genome project will produce information that will allow people to detect genetic susceptibilities before there is agreement on how that knowledge should be used. Action based on nascent results makes the potential misuse considerable. Implied meaning of genetic behavioural potentials, given the wrong political climate, can doom groups already struggling to overcome social injustice to further abuse as the public looks for a quick genetic fix instead of attempting the more difficult social changes that need to be made.

Scientists therefore need to show greater vigilance and responsibility, especially concerning public perception of their work. More cautious pictures of the impact of findings and more focus on the limitations of results will help. Scientists do have a history of responsible public action; just over twenty years ago, scientists concerned about the potential dangers of recombinant DNA technology set guidelines to prevent misuse. The data created by the human genome project has a potential for misuse as well. A good beginning to address these issues is provided by Eric Lander and Leonid Kruglyak in this issue (p. 241), which offers formal guidelines for the criteria that should be used to define significant linkage to complex traits. These suggestions have been widely circulated within the community before publication and appear to have a wide consensus among researchers.

In addition to reaching an accord on how to define data, researchers should ensure that the language they use to describe their work avoids bringing prejudices to life. The concern at the meeting about the phrase 'genetics of crime' may seem merely semantic, but it carries an inherent bias to the public, creating a perceived intent. Furthermore, 'crime' is not an appropriate term for these studies; as Frank Zimring of the University of California Law School and others pointed out, studying the genetic basis of crime per se is unlikely to produce meaningful results, for crime is a vague phenotype that is socially defined (thus subject to bias) and difficult to measure.

Although the Maryland meeting had its difficulties, this should not prevent similar conferences. The concern that simply discussing these issues will add weight to an already growing movement to abandon the inner cities is not wholly ungrounded; however, failure to address the implications of the human genome project would be a tragic mistake. 